\title{
Dietrich Bonhoeffer: uma inspiração para a práxis política e social da Igreja
} Dietrich Bonhoeffer:
an inspiration for the Church's political and social
práxis Gerson Lourenço Pereira

\section{Resumo}

Partindo das concepções eclesiológicas, militância e espiritualidade do teólogo alemão Dietrich Bonhoeffer (1906-1945), o presente artigo busca compartilhar as fontes inspirativas para a práxis eclesial frente aos desafios sociais e políticos que se apresentam nos contextos latino-americano e brasileiro na atualidade. Decisivamente, há uma dimensão profético-libertadora a ser assumida pela Igreja hoje, o que requisita sólida base teológica e olhar crítico consciente sobre a realidade. Bonhoeffer é, pois uma voz que ecoa influenciando o engajamento de pessoas e grupos nas exigências de luta por justiça, igualdade e paz. Dessa forma, o texto faz uma rápida passagem pela biografia pessoal, acadêmica e ministerial de Bonhoeffer, interrompida pelo martírio em razão da sua adesão à resistência contra o regime Nazista, durante a Segunda Grande Guerra. Sequencialmente, ocupando-se em pontuar os principais aspectos do seu pensamento eclesiológico, finaliza com a apresentação de luminosas inspirações para a atuação da Igreja cristã nos tempos atuais, em um convite para o reconhecimento de uma realidade crítica como desafio pastoral.

Palavras-chave: Dietrich Bonhoeffer. Trajetória. Eclesiologia. Espiritualidade militante. 


\begin{abstract}
Starting from the ecclesiological conceptions, militancy and spirituality of the German theologian Dietrich Bonhoeffer (1906-1945), the present article seeks to share the inspiring sources for ecclesial praxis in the face of the social and political challenges that are present in the Latin American and Brazilian contexts today. Decisively, there is a prophetic-liberating dimension to be assumed by the Church today, which requires a solid theological basis and a conscious critical look at reality. Bonhoeffer is therefore a voice that echoes influencing the engagement of people and groups in the demands of the struggle for justice, equality and peace. Thus, the text makes a quick passage through Bonhoeffer's personal, academic and ministerial biography, interrupted by martyrdom due to his adhesion to the resistance against the Nazi regime, during World War II. Sequentially, occupying himself with punctuating the main aspects of his ecclesiological thinking, he ends with the presentation of luminous inspirations for the work of the Christian Church today, in an invitation to recognize a critical reality as a pastoral challenge.
\end{abstract}

Keywords: Dietrich Bonhoeffer. Trajectory. Ecclesiology. Militant spirituality.

\title{
Introdução
}

Compreender a missão da Igreja no mundo, sobretudo diante dos contrastes e das injustiças que figuram em realidades, como as do "sul continental", exige um olhar sensível e ações concretas, firmes. Uma postura que conjugue a confissão de fé e o compromisso social, ${ }^{1}$ em diálogo com todas as iniciativas convergentes para a promoção humana e a dignificação dos sujeitos, impulsionada pela espiritualidade do serviço, dos olhos abertos e das mãos operantes.

Para a concretização dessa práxis eclesial, importa o resgate de figuras paradigmáticas, testemunhas notáveis da fé cristã. Referências históricas cuja vida, ação e obras inquietem e inspirem o Povo de Deus hoje a submergir e, quiçá, subverter contextos nos quais a opressão e injustiças sejam evidentes. O teólogo alemão Dietrich Bonhoeffer (1906-1945) é, pois, um desses

${ }^{1}$ EG 178. 
ícones cuja espiritualidade vivida esteve integrada a uma sólida reflexão e à militância, constituindo-se numa fonte luminosa de inspiração.

Observando sua trajetória teológica, nota-se quão constante fora a busca pelas concreções da Revelação nos vários momentos e etapas de sua biografia pessoal, ministerial e acadêmica. Trajetória essa infelizmente interrompida, como consequência de sua opção pastoral que o conduziu a aderir à conspiração contra Hitler e o regime Nazista na Alemanha. Apesar de tal interrupção, Bonhoeffer deixou um legado original para a teologia cristã do Século XX, construído sobre o alicerce eclesiológico. Para ele, o lugar da concreção da revelação seria a Igreja ${ }^{2}$ na qual as expectativas em relação aos sinais do Reino se evidenciariam, trazendo sentido para o fazer teológico e fecundando sua práxis.

Compreender e refletir a respeito do legado bonhoefferiano implica, portanto, na conexão entre o fazer e pensar teológicos com uma biografia marcada pela resistência, luta e martírio. Assim, neste artigo serão ressaltadas as contribuições profético-libertadoras deixadas por este teólogo para a Igreja na atualidade. Visando alcançar tal finalidade, o primeiro passo será apresentálo, destacando brevemente os principais acontecimentos circundantes de sua jornada pessoal, acadêmica e militante. $\mathrm{O}$ segundo passo consistirá na exposição dos aspectos eclesiológicos que sustentam sua reflexão teológica. No terceiro e último passo, em um exercício de contextualização, serão buscadas, na eclesiologia concebida por Bonhoeffer, as inspirações para o engajamento eclesial, fomentadora de uma espiritualidade profético-militante frente aos múltiplos desafios pastorais da atualidade no contexto latinoamericano e brasileiro.

\section{Breve biografia de Dietrich Bonhoeffer ${ }^{3}$}

Quem foi Dietrich Bonhoeffer? "Discípulo, testemunha e mártir". Alguém que deixou marcas para a teologia e para a ação pastoral, definido

\footnotetext{
${ }^{2}$ APPEL, K.; CAPOZZA, N., "Estar-aí-para-outros" como participação da realidade de Cristo, p. 584.

${ }^{3}$ Nesta seção e na próxima são retomadas algumas ideias desenvolvidas no terceiro capítulo da tese de doutorado, defendida em 2014, no departamento de Teologia da PUC-Rio, na qual se estabelece o legado e pensamento de Dietrich Bonhoeffer como referencial teórico para o estudo pretendido. PEREIRA, G. L., Uma igreja cristocêntrica, diaconal e koinônica.

${ }^{4}$ Título dado a uma coletânea de escritos de Dietrich Bonhoeffer reunidos para meditações. MALSCHIZKY, H., Dietrich Bonhoeffer. Também: SLANE, G., Bonhoeffer, o Mártir.
} 
por Ebehard Bethge, contemporâneo e amigo pessoal, como um "teólogo, cristão e homem do seu tempo". ${ }^{5}$ Luterano, nascido em 04 de Fevereiro de 1906, em Breslaw, foi laureado em Teologia Dogmática em 1927 e, no ano seguinte, aprovado em seu primeiro exame eclesiástico, iniciando o vicariato em Barcelona, Espanha, sendo designado, em seguida, como estagiário para uma paróquia em Berlim de 1929 a 1930, quando foi habilitado como docente na Universidade. No mesmo ano, em 1930, recebeu uma bolsa de estudos nos Estados Unidos e ingressou no Union Theological Seminary, em Nova York. ${ }^{6}$

De 1931 a 1933, Dietrich Bonhoeffer iniciou a prática docente na Faculdade de Teologia da Universidade de Berlim. Esse foi um período fecundo na sua trajetória teológica. No primeiro ano teve o primeiro contato pessoal com Karl Barth em Bonn, foi eleito secretário para o movimento da juventude na Conferência Ecumênica de Cambridge (na Inglaterra) e ordenado ministro luterano. Em 1932, participou da Conferência Internacional da Juventude, em Gland, na Suíça, onde discursou o tema: "A Igreja está morta”. Como Livre-Docente em Berlim, Bonhoeffer, ministrou vários cursos de grande valia para os estudos teológicos contemporâneos, dentre os quais: "História da Teologia Sistemática no Século XX", "A Essência da Igreja", "Existe uma Ética Cristã?", "Criação e Queda", "Cristologia".7

Em 30 de janeiro de 1933, Adolf Hitler tornou-se chanceler do Reich. Bonhoeffer se opôs radicalmente, iniciando uma jornada de contestação, resistência e militância contra o Nacional Socialismo alemão junto à Igreja Confessante, organizada como contraposição ao vínculo eclesiástico de tradições distintas com o Estado. ${ }^{8}$ Em 1935 Bonhoeffer assumiu a direção

\footnotetext{
${ }^{5}$ BETHGE, E., Dietrich Bonhoeffer, p. 677.

${ }^{6}$ BETHGE, E., Dietrich Bonhoeffer, p. 45-169.

${ }^{7}$ MILSTEIN, W., Dietrich Bonhoeffer, p. 27-28; BETHGE, E., Dietrich Bonhoeffer. p. 173-323.

${ }^{8}$ MILSTEIN, W., Dietrich Bonhoeffer, p. 35; BETHGE, E., Dietrich Bonhoeffer, p. 263-268; p. 304-323. A Igreja Luterana, naquele momento, estava dividida. Havia um bom número de partidários do nacional-socialismo, os "teuto-cristãos", que ensejavam incorporar o "Princípio do Líder" (Führerprinzip). O candidato dessa ala, Ludwig Muller, foi eleito em 27 de setembro de 1933, com 70\% dos votos, como bispo nacional. (MILSTEIN, W., Dietrich Bonhoeffer, p. 38-40). No ano seguinte, de 29 a 31 de maio, 138 delegados provenientes das igrejas territoriais se reuniram em Barmen e acolheram uma proposta elaborada por Karl Barth, conhecida como a "Confissão de Barmen", sendo com isso também organizada a Igreja Confessante. Em face da conjuntura eclesiástica na Alemanha, naquele mesmo ano foi preparada a Liga Pastoral de Emergência, sob a liderança de Martin Niemöller, que protegeu os ministros de descendência judia, enquanto a Igreja Territorial da Prússia em 6 de setembro assumia, em assembleia, o Parágrafo Ariano (MILSTEIN, W., Dietrich Bonhoeffer, p. 41; BETHGE, E., Dietrich
} 
de um dos seminários da Igreja Confessante, criando mais tarde a Casa da Irmandade em Fikenwalde. No ano de 1937 tanto o seminário como a irmandade foram fechados pela Gestapo e 27 alunos encarcerados.

Em 1938, Bonhoeffer teve sua permanência em Berlim interditada, “exilando-se" nos Estados Unidos. 9 Após rápida estada na América do Norte, regressou à Alemanha em 1939, ingressando assim na Abwehr. ${ }^{10}$ Em 1940, foi proibido de discursar e ensinar, sendo obrigado a anunciar os seus deslocamentos dentro do território alemão. Ainda assim militou na resistência, viajando à Suíça em missão junto ao movimento ecumênico para discutir a respeito da rendição da Alemanha entre os anos de 1941 e $1942 .{ }^{11}$

Em 1943, após falharem dois atentados contra Hitler (13 e 21 de março do mesmo ano), nos quais consentiu e participou da articulação, Bonhoeffer foi preso juntamente com seu cunhado, Hans von Dohnanyi, sendo transferidos em seguida para a prisão em Tegel. ${ }^{12}$ Após outros sucessivos deslocamentos, provocados pela descoberta do dossiê de $Z_{o s s e n}{ }^{13}$ e a falha de um último atentado contra Hitler, ${ }^{14}$ no dia 5 de abril, foi ordenada pelo próprio Führer a execução de todos os participantes dos atentados. Assim, na manhã de 9 de abril de 1945, em Flossenburg, Dietrich Bonhoeffer foi enforcado. Sete dias depois, Hitler se suicidou e no dia 7 de maio o III Reich foi derrotado pelas Forças Aliadas. ${ }^{15}$

Bonhoeffer, p. 366-372).

${ }^{9}$ MILSTEIN, W., Dietrich Bonhoeffer, p. 46-61; BETHGE, E., Dietrich Bonhoeffer, p. 419-678.

${ }^{10}$ Foi o serviço de contra-espionagem das Forças Armadas Alemãs liderada pelo Almirante Walter-Wilhelm Canaris que se tornou o núcleo de resistência contra Hitler e seu regime. A respeito da $A b w e h r$, a liderança de Canaris e as iniciativas da resistência alemã na Segunda Guerra: BASSET, R., Almirante Canaris.

${ }^{11}$ BETHGE, E., Dietrich Bonhoeffer, p. 681-797.

${ }^{12}$ Além de Bonhoeffer e Dohnayi foram encarcerados pela Gestapo Wilhelm Canaris e Hans Oster, os demais integrantes da Abwehr. MILSTEIN, W., Dietrich Bonhoeffer, p. 79; BETHGE, E., Dietrich Bonhoeffer, p. 799-891.

${ }^{13}$ Trata-se de uma série de documentos descobertos pela Gestapo escondidos em um porão em Zossen, no sul de Berlim. Nesses documentos constavam os diários do Almirante Canaris; os prontuários médicos de Hitler, incluindo uma avaliação negativa sobre a sua sanidade mental emitido na Primeira Guerra quando fora intoxicado por gás; relatórios a respeito das atrocidades alemãs compiladas por Dohanyi e outros membros da Abwehr; e os registros das conversas de Bonhoeffer na Suécia e Suíça com agentes ingleses e das suas negociações através do Vaticano. A descoberta do dossiê de Zossen desencadeou a captura dos envolvidos na resistência alemã e no fim da Abwehr (BASSET, R., Almirante Canaris, p. 282-283).

${ }^{14}$ Resultado malsucedido do que ficou conhecido como "Operação Walkíria".

${ }^{15}$ BETHGE, E., Dietrich Bonhoeffer, p. 893-933. 
Correspondendo a uma espiritualidade profundamente arraigada na tradição profética de anúncio, denúncia e engajamento, as etapas da biografia de Dietrich Bonhoeffer fizeram eclodir as fases progressivas no seu pensamento teológico. Prócoro Velasques defendeu uma evolução convergente na ética. ${ }^{16}$ Tal convergência, entretanto, manteve subjacente sua preocupação eclesiológica, o que foi determinante para as suas reflexões ao longo de sua trajetória.

Segundo André Dumas, a uma certa altura Bonhoeffer buscou "uma Igreja para os não religiosos", ocupando-se em destacar sua presença e atuação no mundo e na sociedade secular, sendo considerado por Dumas como "o teólogo das dimensões comunitárias da existência cristã". ${ }^{17}$ A proclamação de que a Igreja estava morta, em 1932, não indicou sua apostasia eclesial, mas o rompimento eclesiástico, com a dimensão visível, denominacional, hierárquica que caminhava para uma associação contraditória com o projeto necropolítico ${ }^{18}$ do III Reich. Associação esta que implicava na perda de sua essência, sobretudo no que se refere à dimensão proclamativa e testemunhal do Reino de Deus diante de um quadro político autoritário, injusto e opressor.

Digno de nota, confirmando sua preocupação com a adesão eclesiástica ao projeto de poder na Alemanha Nazista, é o registro de dois episódios emblemáticos da caminhada de Bonhoeffer. O primeiro foi uma transmissão ao vivo em rádio, no dia $1^{\circ}$ de fevereiro de 1933 (dois dias depois da ascensão de Hitler) na qual desenvolvia o tema "A Evolução da Noção de Líder (Führer)". Fazendo um trocadilho, advertiu: "Se o Führer se deixar levar pelos governados a ser o seu ídolo - e o governado sempre esperará isso dele -, a imagem do líder (Führer) descambará para a do tentador (Verführer)... Governante e governo que se divinizam afrontam a Deus". Por esse motivo, a palestra foi interrompida antes do seu término. ${ }^{19}$

O outro acontecimento foi sua reação frente à proclamação da Lei Ariana, dois meses depois, no dia 7 de abril de 1933, pelo governo. Recebendo o nome oficial de "Decreto para Recomposição do Funcionalismo Público", esse dispositivo legal consistiu na demissão de todos os servidores públicos

\footnotetext{
${ }^{16}$ VELASQUES, P., Uma ética para os nossos dias, p. 15-18.

${ }^{17}$ DUMAS, A.; BOSC, J.; CARREZ, M., Novas Fronteiras da Teologia, p. 108-109.

${ }^{18}$ Termo cunhado pelo filósofo, historiador e cientista político camaronês Achille Mbembe. Significa a adoção da prática do extermínio, da política da morte adaptada pelo próprio Estado (MBEMBE, A., Necropolítica).

${ }^{19}$ BETHGE, E., Dietrich Bonhoeffer, p. 263-268.
} 
não-arianos (judeus de fé, de descendência e seus respectivos cônjuges) das repartições do Estado. ${ }^{20}$ Pouco tempo depois, no mesmo mês, atentando para o antissemitismo que prefigurava em seu país, Bonhoeffer escreve e discursa sobre dois temas: "A Igreja e a Questão dos Judeus" e "O Parágrafo Ariano na Igreja". O teor dessas reflexões foi constituído em três eixos fundamentais, dizendo respeito à posição desejada que fosse assumida pela Igreja sobre a relação do Estado com os judeus: $1^{\circ}$ - a Igreja deveria se perguntar sobre a legitimidade da ação do Estado; $2^{\circ}$ - o compromisso da igreja deveria ser com as vítimas que pertencessem ou não aos círculos eclesiásticos; $3^{\circ}$ - a responsabilidade da igreja não seria apenas de cuidar das "vítimas da roda, mas de se atirar nos raios dessa roda". ${ }^{21}$

Consente-se, portanto, que Dietrich Bonhoeffer nunca abandonou o tema da eclesiologia. Simultaneamente fonte de preocupação, no que se refere à atuação frente à realidade crítica no cenário social e político que figurava; e chave para compreender sua produção teológica diante do desafio da atualização da Revelação nesse contexto. Dessa forma, no passo a seguir deste artigo, serão pontuados os aspectos constitutivos da sua concepção eclesial.

\section{Aspectos do pensamento eclesiológico de Bonhoeffer}

Compreender o pensamento eclesiológico de Bonhoeffer implica a apreensão da fase mais amadurecida e crítica de sua reflexão, denominada por Eberhard Bethge como Nova Teologia, construída e constituída ao longo do período em que esteve preso, próximo do seu martírio. ${ }^{22}$ Neste despontam três importantes temas: "O mundo tornado adulto", "A Disciplina Arcana" e a "Interpretação não-religiosa dos conceitos bíblicos". Sobre este último, Bethge menciona:

A frase foi usada pela primeira vez no último ano de sua vida, quando um novo impulso o moveu para reexaminar sua teologia. Essa nova abordagem possibilitou que avançasse, em total contraste com a situação em que se encontrava naquele momento. Ele foi atraído pela situação a produzir um novo trabalho teológico. ${ }^{23}$

\footnotetext{
${ }^{20}$ BETHGE, E., Dietrich Bonhoeffer, p. 304-323.

${ }^{21}$ MILSTEIN, W., Dietrich Bonhoeffer, p. 35-38.

${ }^{22}$ BONHOEFFER, D., Resistência e Submissão.

${ }^{23}$ BETHGE, E., Dietrich Bonhoeffer, p. 853-854.
} 
A respeito da ideia de um "mundo tornado adulto", não caberia mais a utilização de linguagens metafísicas provenientes do classicismo cristão. Nesse sentido, Bonhoeffer recusa a "tutoria de Deus", ${ }^{24}$ bem como o "deus ex machina" 25 ou "tapa buracos".

Sobre a "Disciplina Arcana", de acordo com o levantamento temático de Eberhad Bethge, desponta nas suas novas reflexões de Bonhoeffer como resposta em relação ao lugar da identidade cristã frente à interpretação não religiosa dos conceitos bíblicos e dogmáticos. "O que significam o culto e a oração na arreligiosidade? Ou, em um mundo tornado adulto? (...) A disciplina arcana ou a distinção entre último e penúltimo adquirem nova importância neste sentido?". ${ }^{26}$ Tratar-se-ia da fonte primitiva onde estão depositadas as percepções da igreja antiga, os princípios que guardam a essência da Igreja e são transmitidos pelo catecumenato. Bonhoeffer utiliza essa expressão em termos da confissão eclesiástica. Velasques, ao referir-se ao conceito, aponta para duas finalidades: "proteger a fé cristã contra a profanação e fazer distinção entre aquilo que é essencial e aquilo que não é". ${ }^{27}$

Diante dessas ideias, pinçadas na etapa martirial da sua caminhada, de que forma se situa a eclesiologia refletida por Bonhoeffer? Que aspectos, uma vez iluminadas pelas ênfases pontuadas, são desvendadas no seu pensamento eclesial que alicerçam seu construto teológico? Estabelecendo como base o conteúdo parcial de algumas obras de Bonhoeffer, compreendidas a partir da chave hermenêutica disposta nas conceituações forjadas da sua fase derradeira, alcançam-se as seguintes concepções eclesiológicas: Igreja como comunhão dos santos, lugar da Revelação, representação de Cristo e em relação ao mundo. No que consistem?

\footnotetext{
${ }^{24}$ BONHOEFFER, D., Resistência e Submissão, p. 432.

${ }^{25}$ BONHOEFFER, D., Resistência e Submissão, p. 373 - Literalmente quer dizer "o Deus que sai da máquina". "Deus não é um tapa-furos; Deus tem de ser conhecido não apenas nos limites de nossas possibilidades, mas no centro da vida; Deus quer ser reconhecido na vida e não apenas na morte, na saúde e na força e não apenas no sofrimento, na ação e não apenas no pecado. A razão disso está na revelação de Deus em Jesus Cristo. Ele é o centro da vida, e de modo algum 'veio para' trazer-nos a resposta para questões não resolvidas. A partir do centro da vida, certas perguntas até mesmo caem por terra e, da mesma forma, as respostas a essas perguntas”. BONHOEFFER, D., Resistência e Submissão, p. 415-416.

${ }^{26}$ BONHOEFFER, D., Resistência e Submissão, p. 371-372.

${ }^{27}$ VELASQUES, P., Uma ética para os nossos dias, p. 86.
} 


\subsection{Igreja como Comunhão dos Santos}

Segundo Karl Rahner, a Igreja é a tangibilidade histórica da presença de Deus que se autocomunica, onde o cristão experimenta-a como o lugar do amor, do amor para com Deus e para com o próximo, experienciados como dádivas; a Igreja é o lugar, a garantia, a expressão histórica de que Deus nos ama. ${ }^{28}$ Tal experiência é feita fundamentalmente na relação com o próximo.

A concepção eclesial rahneriana como realidade temporal da manifestação do amor a Deus e ao próximo, e de Deus no próximo, insere uma demarcação epistemológica da Igreja, a ser considerada em perspectiva comunitária. Essa perspectiva é estabelecida em termos conceituais por Bonhoeffer: a Igreja é o espaço de vida em comunhão.

Conforme Bonhoeffer assinalou em "A comunhão dos santos", tese defendida em 1927, a Igreja é Cristo vivendo como comunidade. Em que termos, então, é vista a comunhão dos santos? "Comunhão cristã é comunhão por meio de Jesus Cristo e em Jesus Cristo... Pertencemos uns aos outros tão somente por meio de e em Jesus Cristo". ${ }^{29}$ Além da pertença exclusiva de Jesus Cristo (base cristológica que será abordada adiante), a Igreja é a comunhão dos santos onde o ser humano, no afã do encontro com Deus, encontra o próximo. Essa concepção traz, pelo menos, duas implicações integradas.

Uma implicação é a distinção entre Igreja e comunidade religiosa. Segundo Bonhoeffer, "a igreja é uma realidade da fé", ao passo que a comunidade religiosa se põe como "ideal da experiência" $\cdot{ }^{30}$ Como realidade da fé, a Igreja é comunidade de amor vivido a partir da fé em Cristo, direcionado ao outro. ${ }^{31}$ É onde se vive com e para os outros, a serviço do próximo.

A outra implicação é como o próximo é reconhecido. Quem vive em comunidade se abre tanto para a realidade da Palavra (por meio do que Cristo se revela), como para a do outro (em dimensão ética). Da Palavra de Deus ouve-se o imperativo de servir ao próximo, pois é nele que Deus se revela a nós, sendo este todo aquele que necessita de nós. ${ }^{32}$ Seguindo a definição

${ }^{28}$ RAHNER, K., Curso Fundamental da Fé, p. 462.

${ }^{29}$ BONHOEFFER, D., Vida em Comunhão, p. 12.

${ }^{30}$ BONHOEFFER, D., Creer y Vivir, p. 56.

${ }^{31}$ BONHOEFFER. D., Sociologia de La Iglesia, p. 124-125. Tese defendida por Bonhoeffer em 1927, para obtenção de sua licenciatura em Teologia na Universidade de Berlim. Recentemente traduzida para o português por Nélio Shcneider, publicada como: BONHOEFFER, D., A comunhão dos santos.

${ }^{32}$ VELASQUES, P., Uma ética para os nossos dias, p. 25. 
de sacramento como um ato de salvação pessoal do próprio Cristo, que se torna presente e age pessoalmente, nota-se uma percepção sacramental na concepção do próximo. ${ }^{33}$

Por meio do viver comunitário responsável da fé na e pela Igreja, na e pela comunidade de fé, se obtém a salvação.

\subsection{Igreja como Lugar da Revelação}

Diante da indagação a respeito da Igreja como Revelação de Deus, Bonhoeffer une a concepção católica da Igreja como ser à concepção do caráter interpelativo, como ato, de Karl Barth, respondendo também à pergunta sobre o lugar eclesial.

Se deve falar ao mesmo tempo de ser e ato da Igreja. Ao perguntar pela Igreja como lugar de Deus no mundo, perguntamos ao mesmo tempo pela interpelação e pela essência, o ato e o ser. Deus está, na medida em que podemos imaginá-lo, em um lugar: em Cristo, na Igreja, na Palavra da pregação. ${ }^{34}$

Bonhoeffer enxergava a Igreja situada no mundo, não em um lugar distinto ou privilegiado, mas onde o Cristo presente na vida comunitária, sob a Palavra de Deus e através dos sacramentos se manifesta. ${ }^{35}$ A tríplice base constitutiva comunhão, Palavra e sacramentos independem de uma instituição para o seu oferecimento, sendo o lugar apropriado aquele designado pela benigna presença de Deus, no lugar onde o ser humano fizer a experiência relacional com Ele, operada e sinalizada por tais elementos. ${ }^{36}$ Entretanto, quem se encarrega por oficiar os meios de Graça e com isso acessar os indivíduos à Revelação divina?

No princípio do sacerdócio comum de Lutero e da Reforma Protestante, Bonhoeffer não enxerga a necessidade do descarte da figura do sacerdote. Este

\footnotetext{
${ }^{33}$ Assim Bethge observa no pensamento bonhoefferiano a sacramentalidade do próximo, ou seja, um verdadeiro meio de Graça que Deus oferece em Jesus Cristo, que se torna o outro, o que necessita e o que comunga, em direção a nós, por meio de quem Deus vem ao nosso encontro revelando seu intento salvífico (VELASQUES, P., Uma ética para os nossos dias, p. 25).

${ }^{34}$ Fundamentalmente em "Ato e Ser" que a Igreja é conceituada como espaço da concreção da Revelação de Deus pela Palavra. Deus se revela na Igreja e pela Igreja, cabendo uma indagação fundamental: onde se situa essa Igreja que é ao mesmo tempo depositária e proclamadora da Revelação? (BONHOEFFER, D., Act and Being).

${ }^{35}$ BONHOEFFER, D., Vida em Comunhão, p. 62.

${ }^{36}$ BONHOEFFER, D., Creer y Vivir, p. 28.
} 
é visto como o ministro que se encarrega de apresentar-se diante de Deus por toda a comunidade e mantê-la unida estreitamente em comunhão, que se torna a forma de proclamação de Cristo pela e na estrutura comunitária. A comunhão com Deus e com o irmão na fé, em linhas vertical e horizontal, são inseparáveis, mantidas e atualizadas pelo Espírito Santo. "A comunidade do irmão com o irmão é a atualização, por meio do Espírito proclamador, da igreja realizada na representação de Cristo", ${ }^{37}$ onde a Trindade se manifesta nas formas imanente e econômica.

\subsection{Igreja como Representação de Cristo}

Deus reúne todo gênero humano para viver em comunidade através de Jesus Cristo, que existe no mundo na forma da comunidade de fé, sendo ela a forma possível de Cristo na história até a sua parusia. ${ }^{38}$ Ela é o corpo vivo e total de Cristo, onde não é somente a cabeça, para onde toda a humanidade é convidada a convergir onde se mostra inaugurada a nova humanidade, o povo novo. ${ }^{39} \mathrm{Na}$ comunidade se dá a continuidade da existência histórica de Jesus, o que a torna praticamente portadora permanente, em constante atualização, da imanência de Cristo no mundo. ${ }^{40}$

Cristo adquire forma na Igreja, segundo as palavras de Bonhoeffer:

A Igreja está firmada em e por Cristo, que, com sua ação representativa, é ao mesmo tempo indivíduo e humanidade. A representação de Cristo significa aquela ação em que ele se coloca em nosso lugar, onde nós deveríamos estar frente a Deus. Representação, em sentido ético, é sacrifício de bens. Na ação de Cristo tem lugar um sacrifício pessoal. Enquanto representante, Cristo atua como a nova humanidade, e nele está assentada a Igreja... A Igreja está fundada na realidade de sua ação representativa como homem-Deus. ${ }^{41}$

Ao mesmo tempo, Jesus Cristo é a comunidade, Senhor dessa comunidade e irmão na comunidade pela encarnação, pelo cumprimento da lei, na cruz e ressurreição. Trata-se de uma representação que, uma vez posta diante dos

${ }^{37}$ BONHOEFFER, D., Creer y Vivir, p. 68-69.

${ }^{38}$ VELASQUES, P., Uma ética para os nossos dias, p. 24.

${ }^{39}$ BONHOEFFER, D., Creer y Vivir, p. 39.

${ }^{40}$ VELASQUES, P., Uma ética para os nossos dias, p. 25.

${ }^{41}$ BONHOEFFER, D., Creer y Vivir, p. 51 (os grifos são do autor deste artigo). 
desafios da humanidade, exorta a Igreja a um agir responsável como ser de Cristo pelo exercício do ministério da pregação evangélica e testemunho no mundo. Onde se encontra?

A comunidade cristã está no lugar onde o mundo todo deveria estar; nesse sentido, ela serve representativamente ao mundo e existe em função dele. Por outro lado, o mundo chega à sua própria plenitude onde está a comunidade (...) a 'nova criação', 'a nova criatura', o alvo dos caminhos de Deus na terra. Nessa dupla representatividade está a comunidade, inteiramente na comunhão e no discipulado do seu Senhor, que foi o Cristo precisamente no fato de existir totalmente para o mundo e não para si mesmo. $^{42}$

Sobre a representação vicária da Igreja, Appel e Capozza apontam para três consequências ontológicas decisivas, oriundas dos escritos da prisão: o ser da Igreja consiste em "estar aí para os outros"; em não se afirmar apenas na autodefesa; e em assumir "a perspectiva a partir de baixo". ${ }^{43}$

\subsection{Igreja em Relação ao Mundo}

A Igreja concreta é uma realidade mundana resultante da encarnação de Cristo $^{44}$ cujas fronteiras distintivas com Reino de Deus e com o Estado não subtraem a sua essência imanente. Sua atuação como mandato de Deus é histórica, temporal, inserida na realidade. Consequentemente, a proposta eclesial de Bonhoeffer se apresenta na relação com mundo em algumas perspectivas.

A primeira é a perspectiva integrada. Bonhoeffer não é dualista na maneira como concebe a realidade, rejeitando o "pensamento espacial", fugindo da dicotomia entre sagrado e profano, Igreja e mundo, cristianismo e paganismo. Essa recusa ao dualismo faz surgir uma concepção da história salvífica: história da salvação e história humana integram a mesma realidade.

A proposta eclesial bonhoefferiana, em relação ao mundo, também se concebe em perspectiva humanizadora. Para o exercício do mandato de Deus no mundo, a realidade se torna o elemento fundamental para a visibilidade

${ }^{42}$ BONHOEFFER, D., Ética, p. 165.

${ }^{43}$ APPEL, K.; CAPOZZA, N., "Estar-aí-para-outros" como participação da realidade de Cristo, p. 594.

${ }^{44}$ BONHOEFFER, D., Creer y Vivir, p. 81. 
da Igreja e meio na qual a salvação de Jesus Cristo é concretizada. Nessa ambiência o ser humano é encontrado envolto nas vicissitudes de sua existência e visto pelo "olhar a partir debaixo", chamado assim a integrar a realidade de Cristo, que é a realidade humana em sua plenitude.

Outra é a perspectiva mediadora. Em sua imersão na realidade, a Igreja mundana testemunha a impotência da cruz, tornando-se a propulsora da maioridade do mundo, apontando o caminho da recusa do deus ex machina e que conduz os indivíduos a uma "interpretação não-religiosa dos conceitos bíblicos", potencializando-os à independência e à maturidade da fé.

Appel e Capozza observam na "confissão de culpa", na obra inacabada "Ética", um motivo para esse agir responsável, assim como na "disciplina arcana", que preservaria a essência da Igreja como representação de Cristo no mundo (o penúltimo) e caminho que direciona a esperança escatológica (o último) sem devaneios fundamentalistas, tampouco sem cair num pragmatismo radical que renuncie tal esperança, evitando sua dissolução na realidade.

Pereira, considerando tais concepções, sistematizou sua eclesiologia em três dimensões pastorais, a saber: comunhão (koinonia), centralidade na pessoa de Cristo (cristocentrismo) e serviço (diaconia).

A comunhão (koinonia) é a consubstanciação de Cristo na realidade humana (cristocentrismo) pelo amor, solidariedade, entrega e serviço ao próximo e a Deus (diaconia). O modelo eclesial concebido por Bonhoeffer é secularizada, porém não secularista; integrada com a realidade, sem, contudo, perder sua identidade; vicária e ao mesmo tempo redentora; silenciosa, mas presente pela ação responsável, levedando a massa ${ }^{45}$

Dessa forma sistematizada, a eclesiologia bonhoefferiana, sob um olhar da Teologia Prática, conforme o estudo realizado por Pereira, apresenta as linhas pastorais de um modelo eclesial libertador que corresponde aos desafios e imperativos no contexto latino-americano e brasileiro. Modelo que se constitui em um marco teórico para possíveis reflexões sobre a ação da Igreja frente à realidade, bem como uma fonte de inspiração para a espiritualidade militante, contribuindo para o reavivamento da dimensão política da fé através do desempenho do papel profético-libertador. Portanto, avançando para a conclusão deste texto, o último passo consistirá em considerar as inspirações desse modelo eclesial e de tal espiritualidade para a práxis política e social da Igreja hoje.

${ }^{45}$ PEREIRA, G. L., Uma igreja cristocêntrica, diaconal e koinônica, p. 104. 


\section{Inspirações para a práxis política e social da Igreja}

Marcas da realidade na qual se insere a Igreja hoje revelam um cenário que requisita atuação aguerrida, profética, libertadora. Segundo "Relógios da Mulher", ligado ao Instituto Maria da Penha, por exemplo, em 2017, a cada 7.2 segundos registrava-se que uma mulher era vítima de violência física ${ }^{46}$ No mesmo ano, o Ministério dos Direitos Humanos registrava uma denúncia de intolerância religiosa a cada 15 horas, sendo a maioria das vítimas pertencentes às religiões de matriz africana, com $39 \%$ das denúncias. ${ }^{47}$ Somente no primeiro semestre, a Ouvidoria Nacional dos Direitos Humanos recebeu 725 denúncias de violência, discriminação e outros abusos contra a população LGBTQI+. ${ }^{48}$ Conforme levantamento do Atlas da Violência, dois anos antes, o Brasil registrou 59.080 homicídios. Isso significa 28,9 mortes a cada 100 mil habitantes. Entre 2008 e 2018, a taxa de homicídios de pessoas negras subiu $11,5 \% .^{49}$

Frente a esse cenário, convive-se no campo do exercício do poder público com a implementação de um projeto necropolítico e aporofóbico, ${ }^{50}$ pautado em programas conservadores que ignoram as demandas sociais que afligem as camadas e grupos menos favorecidos. Essa mesma agenda excludente conta com a adesão religiosa cristã, representada por católicos e evangélicos, alinhada com tal projeto de poder, sinalizando contradição semelhante da assumida oficialmente por determinadas igrejas na Alemanha nazista. ${ }^{51}$

Violência, intolerância, preconceito, injustiças são traços concretos dessa realidade que evocam as expressões de uma espiritualidade não escapista ou alienada, e sim comprometida da Igreja. Alessandro Rocha definiu Dietrich Bonhoeffer como alguém que exprimiu em sua trajetória de vida,

${ }^{46}$ SOARES, N., Em números, p. 1.

${ }^{47}$ QUEIROZ, C., Polícia registrou 278 denúncias de intolerância religiosa em 2017, p. 1.

${ }^{48}$ RIBEIRO, V., Número de assassinatos de pessoas LGBT em 2017 foi o mais alto da história do país, p. 1.

${ }^{49}$ CARVALHO, C., Apesar da redução do número de homicídios, mortes de negros sobem, p. 8 .

${ }^{50}$ Termo originalmente cunhado e refletido pela Filósofa Adela Cortina, Professora de Ética

e Filosofia Política da Universidade de Valência, Espanha. Designa a aversão aos pobres (á-poros- pobre, sem recursos; fobia-patologia social de recusa e medo) expressada por meios das apolíticas públicas e relações sociais (CORTINA, A., Aporofobia, el rechazo al pobre).

${ }^{51}$ Para uma compreensão lúcida inicial a respeito da relação entre ala religiosa conservadora cristã com o atual projeto de poder refletido na atual política brasileira, recomenda-se o seguinte texto da Magali Cunha: CUNHA, M., Evangélicos na política, p. 1. 
luta e reflexões: uma "espiritualidade da concretude". ${ }^{52}$ Em sua última etapa reflexiva, no poema "Estações no caminho para a liberdade", escrito da prisão, em julho de 1944, partilhou a convicção de que o real deveria ser agarrado corajosamente. ${ }^{53}$ Correspondendo ao modelo eclesial indicado acima, essa experiência de fé, espiritual, se evidencia como inspiradora por ser comunial e diaconal/martirial.

Sendo a Igreja "Cristo existindo como comunidade", ${ }^{54}$ assumindo sua forma na realidade mundana, compreendida como a realidade de Deus, ${ }^{55}$ essa comunidade, que não necessariamente se denominará religiosa, revelará Jesus Cristo em sua face diaconal, como servo que abnegadamente expressa o serviço pelo "olhar a partir de baixo", ${ }^{6}$ aos menos favorecidos, como demonstração do sentido da ontologia eclesiológica que consiste em "estar-aípara-os-outros": "igreja só é igreja quando está aí para os outros". ${ }^{57}$

Quem são aqueles/as cujo olhar eclesial, movido pela espiritualidade profético-militante, se direcionaria? Numa palavra, quais seriam as pautas pastorais que a realidade descrita acima indica? Assumir essa realidade, contemplando na perspectiva dos que sofrem ("estar-aí-para-os-outros") significaria abraçar empaticamente, em um exercício kenótico de identificação, os sujeitos historicamente sujeitados pelas conjunturas injustas, muitas vezes toleradas pelas estruturas eclesiásticas. Consistiria no envolvimento no combate à discriminação étnico-raciais, com fortes reflexos para o diálogo inter-religioso, ao racismo religioso, uma vez que se atente para as pessoas afrodescendentes e suas tradições espirituais. Também na solidariedade, inclusão e participação nas lutas por inserção e reconhecimento dos LGBTQI+'s. Ainda, na luta pela dignidade dos sem-teto, dos sem-terra, das populações indígenas, pela igualdade de gênero.

Revelado, consubstanciado, transubstanciado (!) na comunidade de fé, o próprio Cristo toma a forma visível no compromisso diaconal, assumido até as últimas consequências, de forma vicária-diaconal, junto a tais sujeitos. Essa foi a motivação e o compromisso assumido por Dietrich Bonhoeffer, tornando-o reconhecido como um dos mártires cristãos da justiça e liberdade

\footnotetext{
${ }^{52}$ ROCHA, A., Dietrich Bonhoeffer e a espiritualidade da concretude, p. 698.

${ }^{53}$ BONHOEFFER, D., Resistência e submissão, p. 521.

${ }^{54}$ BONHOEFFER, D., A comunhão dos santos, p. 221.

${ }^{55}$ BONHOEFFER, D., Ética, p. 195.

${ }^{56}$ BONHOEFFER, D., Resistência e submissão, p. 43.

${ }^{57}$ BONHOEFFER, D., Resistência e submissão, p. 512.
} 
do século XX junto a Dom Oscar Romero e Martin Luther King. ${ }^{58}$ Essa seria uma inspiração luminosa para a atuação da Igreja.

É possível identificar a experiência espiritual de Bonhoeffer com a mística profética de anúncio, denúncia e engajamento que extrapola os limites de determinada denominação cristã ou confissão religiosa, sendo a motivação existencial de todo humanista militante. Resgatando o ponto de vista antropológico sobre a mística, a fé e a espiritualidade, estes são aspectos integrantes do humano que o impulsiona a atitudes éticas radicais. Nesse sentido, usando as categorias de Leonardo Boff e Frei Betto, "todo militante é místico e todo místico é militante". 59

A espiritualidade bonhoefferiana da concretude, revelada nas perspectivas comunial, diaconal/martirial, se torna fonte de inspiração para a práxis sóciopolítica da Igreja em três dimensões. A primeira, por meio da proposta da vivência da mística da comunhão local estabelecendo microrrelações ou redes em inúmeros campos como resistência ao intimismo e individualismo, para as formas egoístas de manifestação das experiências de fé. Digno de nota é a experiência compartilhada por Aloysius Pieris de convivência e comunhão inter-religiosa no Siri Lanka onde, a partir da escuta do magistério dos pobres, são constituídas as Comunidades Humanas de Base. ${ }^{60}$ É provável que as vivências comunitárias intra, inter, extra eclesiais no contexto latino-americano e brasileiro sejam prodigiosas no empoderamento dos sujeitos referidos nas pautas pastorais, possibilitando-lhes oportunidade de voz e protagonismo.

O engajamento, na ação fortalecida pela experiência comunitária, seria a segunda dimensão. A inspiração bonhoefferiana aponta para a direção de uma espiritualidade que encontra o sentido na submersão na realidade, provocando a sua subversão. Como Gandhi, Thomas Merton, Dalai Lama, Luther King, a experiência espiritual particular de Bonhoeffer, além de inspiradora é mobilizadora, uma vez que se manifesta coletivamente na identificação do Mistério de Deus, na pessoa de Jesus Cristo, na comunidade. A ação individual corresponde a atuação de todos. O envolvimento pessoal na realidade seria $\mathrm{o}$ engajamento conjunto dos clamores por justiça, igualdade e paz.

\footnotetext{
${ }^{58}$ Como ato em memória aos 10 mártires do século vinte, as estátuas de Bonhoeffer, Luther King e Oscar Romero estão representadas em galeria externa da Abadia de Westminster, em Londres, desde 1997.

${ }^{59}$ BETTO, F.; BOFF, L., Mística e Espiritualidade.

${ }^{60}$ PIERIS, A., Viver e arriscar, p. 17.
} 
Dessa maneira pode ser compreendida a terceira dimensão inspiradora da espiritualidade bonhoefferiana para a Igreja na atualidade, a entrega abnegada. A perspectiva martirial, posicionada em diálogo, é fonte para superação do medo e elemento motivador para a radicalidade do compromisso pelas causas humanitárias e justas. Curiosamente, o que assemelha os/as humanistas quase sempre é o martírio como resultado da sua militância. Um significativo ensinamento espiritual de Bonhoeffer é a confiança como resistência, mesmo diante do fim iminente. O mesmo aprendizado apreendido por Chico Mendes, Dorothy Stang, Marielle Franco. Cabendo, perfeitamente, a seguinte oração:

Deus, a ti clamo de manhã bem cedo. Ajuda-me a orar e concentrar meus pensamentos; não consigo fazer isso sozinho. Dentro de mim está escuro, mas em ti há luz. Eu estou só, mas tu não me abandonas. Eu estou desanimado, mas em ti há auxílio, eu estou inquieto, mas em ti há paz. Em mim há amargura, mas em ti há paciência. Não entendo os teus caminhos, mas tu conheces o caminho certo para mim. ${ }^{61}$

\section{Conclusão}

Dissonante em seu tempo, e por isso profética, a voz de Dietrich Bonhoeffer talvez ecoe hoje nos clamores e afirmações de vários grupos tais como "black lives matter", "cadê Amarildo", "não há cura para o que não é doença", "respeite o meu Axé". Expressões da vivência comunial, engajada e martirial pautadas na expectativa da construção de uma nova realidade. Quem sabe não seja a Igreja para não-religiosos, operante e de olhos abertos? Instâncias legítimas da concreção da Revelação, nascida entre os pobres? Aqueles para quem a opção da Igreja visível deveria ser "mais uma categoria teológica que cultural, sociológica, política ou filosófica". ${ }^{62}$

Caminhando na contramão da visibilidade desejada por tantos segmentos religiosos, associados a poderes vigentes que oprimem e anulam os sujeitos que se inserem nas pautas pastorais, as luzes bonhoefferianas lançadas tracejam uma nova possibilidade eclesial. Uma Igreja encarnada, atuante, corajosa que subverta a realidade e, sendo preciso, não volte atrás se instada a travar as rodas da opressão, da injustiça e tirania!

\footnotetext{
${ }^{61}$ BONHEFFER, D., Resistência e submissão, p.190.

${ }^{62}$ EG 198.
} 


\section{Referências bibliográficas}

APPEL, K.; CAPOZZA, N. “Estar-aí-para-outros” como participação da realidade de Cristo: sobre a eclesiologia de Dietrich Bonhoeffer. Revista Eletrônica da PUCRS, v. 36, n. 153, set. 2006. Disponível em: <https://revistaseletronicas. pucrs.br/ojs/index.php/teo/article/view/1750> Acesso em: 29 ago. 2020.

BASSET, R. Almirante Canaris: misterioso espião de Hitler. Rio de Janeiro: Nova Fronteira, 2007.

BETHGE, E. Dietrich Bonhoeffer: Theologian, Christian, Man for His Times. A Biography. Minneapolis: Fortress Press, 2000.

BETTO, F.; BOFF, L. Mística e Espiritualidade. Rio de Janeiro: Garamond, 2005.

BONHOEFFER, D. Creer y Vivir. Salamanca: Singueme, 1974.

BONHOEFFER, D. A comunhão dos santos: uma investigação dogmática sobre a sociologia da igreja. São Leopoldo: Sinodal / EST, 2017.

BONHOEFFER, D. Act and Being. New York: HaperCollins, 1996.

BONHOEFFER, D. Ética. São Leopoldo: Sinodal, 2001.

BONHOEFFER, D. Resistência e Submissão. São Leopoldo: Sinodal, 2003.

BONHOEFFER, D. Sociologia de La Iglesia: Sanctorum Comunio. Salamanca: Sigueme, 1980.

BONHOEFFER, D. Vida em Comunhão. São Leopoldo: Sinodal, 2003.

CARVALHO, C. Apesar da redução do número de homicídios, mortes de negros sobem. O Globo, Rio de Janeiro, 28 ago. 2020. p. 8.

CORTINA, A. Aporofobia, el rechazo al pobre. Un desafio a la democracia. Barcelona / Buenos Aires / México: Paidós, 2017.

CUNHA, M. Evangélicos na política. Observatório da Imprensa, 25 set. 2012. p. 1. Disponível em: <https://www.observatoriodaimprensa.com.br/ jornal-de-debates/ed713-evangelicos-na-politica/> . Acesso em: 29 ago. 2020. DUMAS, A.; BOSC, J.; CARREZ, M. Novas Fronteiras da Teologia. São Paulo: Duas Cidades, 1969.

FRANCISCO, PP. Exortação Apostólica Evangelii Gaudium sobre o anúncio do Evangelho no mundo atual. São Paulo: Paulinas, 2013. 
MALSCHIZKY, H. Dietrich Bonhoeffer: Discípulo, testemunha, mártir. São Leopoldo: Sinodal, 2006.

MBEMBE, A. Necropolítica. São Paulo: n-1 edições, 2018.

MILSTEIN, W. Dietrich Bonhoeffer: Vida e Pensamento. São Leopoldo: Sinodal, 2006.

PEREIRA, G. L. Uma igreja cristocêntrica, diaconal e koinônica: estudo teológico-pastoral sobre o metodismo na Cidade do Rio de Janeiro. Rio de Janeiro, 2014. 256p. Tese. Faculdade de Teologia, Pontifícia Universidade Católica do Rio de Janeiro.

PIERIS, A. Viver e arriscar: estudos inter-religiosos comparativos a partir de uma perspectiva asiática. São Bernardo do Campo: Nhanduti Editora, 2008.

QUEIROZ, C. Polícia registrou 278 denúncias de intolerância religiosa em 2017. Jornal Capital do Entorno, Goiás, 27 nov. 2018. p. 1. Disponível em: $<\mathrm{http}$ ://www.capitaldoentorno.com.br/policia-registrou-278-denuncias-deintolerancia-religiosa-em-2017/>. Acesso em: 29 ago. 2020.

RAHNER, K. Curso Fundamental da Fé. São Paulo: Paulus, 2004.

RIBEIRO, V. Número de assassinatos de pessoas LGBT em 2017 foi o mais alto da história do país. Brasil de Fato, 19 jan. 2018. p. 1. Disponível em: $<$ https://www.brasildefato.com.br/2018/01/19/numero-de-assassinatos-depessoas-lgbt-em-2017-foi-o-mais-alto-da-historia-do-pais>. Acesso em: 29 ago. 2020.

ROCHA, A. Dietrich Bonhoeffer e a espiritualidade da concretude: janelas para uma teologia prática. Grande Sinal, v. 59, n. 6, p. 693-703, 2005.

SLANE, G. Bonhoeffer, o Mártir. São Paulo: Editora Vida, 2007.

SOARES, N. Em números: a violência contra a mulher brasileira. Estadão, São Paulo, 07 set. 2017. p. 1. Disponível em: <https://emais.estadao.com. $\mathrm{br} / \mathrm{blogs} /$ nana-soares/em-numeros-a-violencia-contra-a-mulher-brasileira/>. Acesso em: 29 ago. 2020.

VELASQUES, P. Uma ética para os nossos dias: origem e evolução do pensamento ético de Dietrich Bonhoeffer. São Bernardo do Campo: EDITEO, 1977. 
Gerson Lourenço Pereira Doutor em Teologia pela Pontifícia Universidade Católica do Rio de Janeiro Docente do Seminário Metodista César Dacorso Filho Rio de Janeiro / RJ - Brasil E-mail: gersonlourenco2000@yahoo.com.br

Recebido em: 29/08/2020

Aprovado em: 16/11/2020 